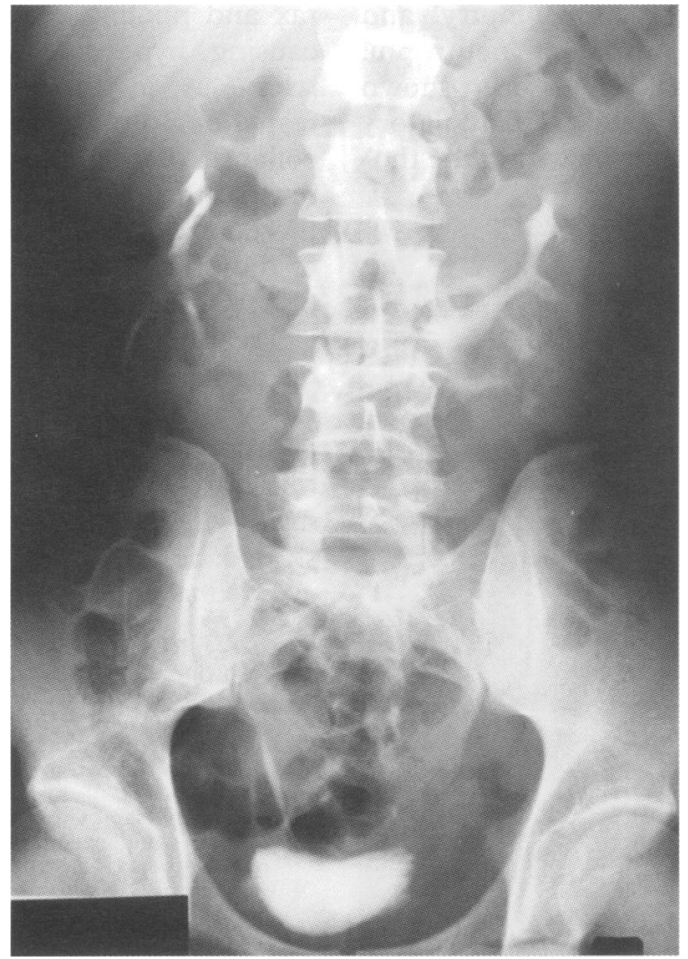

Figure 2 Intravenous urogram showing a horseshoe kidney extravasating from the left lower pole.

lower pole was excised. Postoperatively he made an uneventful recovery.
Horseshoe kidneys occur in $0.25 \%$ of the general population, being twice as common in males. One third to one half of cases are asymptomatic and may be found incidentally. Rarely they may present to the A\&E department after blunt abdominal trauma. The kidney is compressed or fractured across the lumbar vertebrae during a road traffic accident-the "seat belt" syndrome.

Ultrasonography is a well established modality in assessing patients with blunt abdominal trauma. ${ }^{1-3}$ Operator experience and expertise are the two main factors influencing sensitivity and specificity. ${ }^{4}$ This case illustrates that the results of emergency ultrasonography should be viewed with caution in patients identified as having organ anomalies. Remember always to treat the patient and not the ultrasound. If in doubt computed tomography will provide more accurate information provided that the patient is stable.

1 Bode PJ, van Vugt AB. Ultrasound in the diagnosis of injury. Injury 1996;27:379-83.

2 Jehle D, Guarino J, Karamanoukian H. Emergency department ultrasound in the evaluation of blunt abdominal ment ultrasound in the evaluation of

3 Katz S, Lazar L, Rathus V, et al. Can ultrasonography replace computed tomography in the initial assessment of children with blunt abdominal trauma? $f$ Pediatr Surg 1996;5:649-51.

4 Lentz KA, McKenney MG, Nunez DB Jr, et al. Evaluating blunt abdominal trauma: role for ultrasonography. $\mathcal{F}$ Ultrasound Med 1996;6:47-51.

\title{
Intra-orbital foreign body: an unusual route of entry
}

\author{
S B Thakore, U Guly
}

Accident and Emergency

Department, Ninewells Hospital and Medical School, Dundee DD1 9SY

S B Thakore U Guly

Correspondence to: Dr Thakore, Specialist Registrar
A 40 year old man presented with right eye pain, claiming to have been hit in the face with a golf club. Examination revealed a large right periorbital haematoma. The eye was proptosed, his visual acuity was $6 / 5$ in the left eye, but $6 / 36$ in the right eye. Facial radiography showed a radio-opaque intraorbital foreign body on the right side. Examination under anaesthetic by an ophthalmologist showed no evidence of an intraorbital foreign body and no orbital entry site. After computed tomography (fig 1) nasal endoscopy was performed, revealing a laceration of the middle meatus through which the foreign body was removed. Visual acuity in the affected eye improved to $6 / 5$, although minor diplopia remained.

This is the first reported case of a foreign body penetrating the orbit via the nose without leaving an external wound. The usual route of entry of a foreign body is direct penetration through the lower regions of the orbit. ${ }^{1}$ Foreign bodies may be left in place if the patient is asymptomatic. ${ }^{1}$ Removal is indicated in the

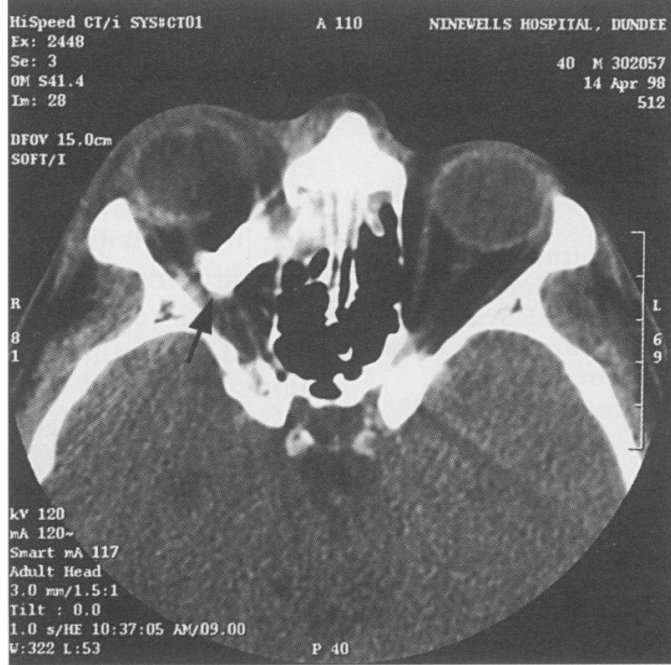

Figure 1 Computed tomography showing a metal foreign body within the right orbit associated with a fracture of the medial wall of the orbit. It is seen lying superior to the optic nerve and lateral rectus, and inferior to medial rectus (arrow). Medial rectus appeared to have been pierced by the foreign body; the globe appeared intact. 
presence of orbital cellulitis, draining fistula, abscess, compressive effects on important orbital structures, persisting inflammation, or communication between orbit and intracranial cavity or paranasal sinuses. ${ }^{12}$

When a patient presents with a clinical picture suggesting an intraorbital foreign body but without a wound, the nose should be considered as a possible route of entry.

1 Holt GR, Holt JE. Management of orbital trauma and foreign bodies. Otolaryngol Clin North Am 1988;21: 35-52.

2 Espaillat A, Enzer Y, Lipsky S. Intraorbital metallic foreign body. Arch Ophthalmol 1998;116:824-5.

\title{
Just a pulled hamstring?
}

\author{
A P Mattick, T F Beattie, M F Macnicol
} Children's NHS Trust, Edinburgh A P Mattick T F Beattie M F Macnicol

Correspondence to: Mr A Mattick, Accident and Emergency Department, Royal Infirmary of Edinburgh, 1 Lauriston Place, Edinburgh EH3 9YW.
The diagnosis of an avulsion of the ischial apophysis in the adolescent is often missed or delayed due to the patient being considered to have sustained a muscular rupture or tendon tear of the hamstring group. ${ }^{1}$ The signs and symptoms of the conditions are similar. However, if there is bony tenderness and swelling at the origin of the hamstrings or a palpable gap in this region, then an avulsion is likely. The avulsion results from the powerful contraction of the hamstring muscles and often occurs during sporting activities. ${ }^{2}$ Between puberty and up to 25 years of age, the ischial apophysis is the weakest link in the chain of muscle, tendon, epiphysis, and bone. Thus it is the most vulnerable site when stressed. ${ }^{3}$ After this age the apophysis fuses with the innominate bone rendering an avulsion a rarity. To illustrate the above we present the following case in a young sportsman.

A 15 year old boy was participating in a sprint relay when he suddenly pulled up due to a sudden pain in his right buttock. He was originally diagnosed as having sustained a strained hamstring muscle and treated conservatively with rest and physiotherapy. Three months later, after no improvement, a plain radiograph showed an avulsion of the right ischial apophysis (fig 1). He was again treated conservatively. At six months after the injury he was referred for an orthopaedic opinion, via our accident and emergency department, because of the difficulty in resuming his pre-injury sporting activities. At this stage operative management was seriously considered but a conservative approach continued after discussion with both patient and his parents. At 10 months after the injury he was asymptomatic despite lack of bony union radiologically.

Recognition of this condition is important

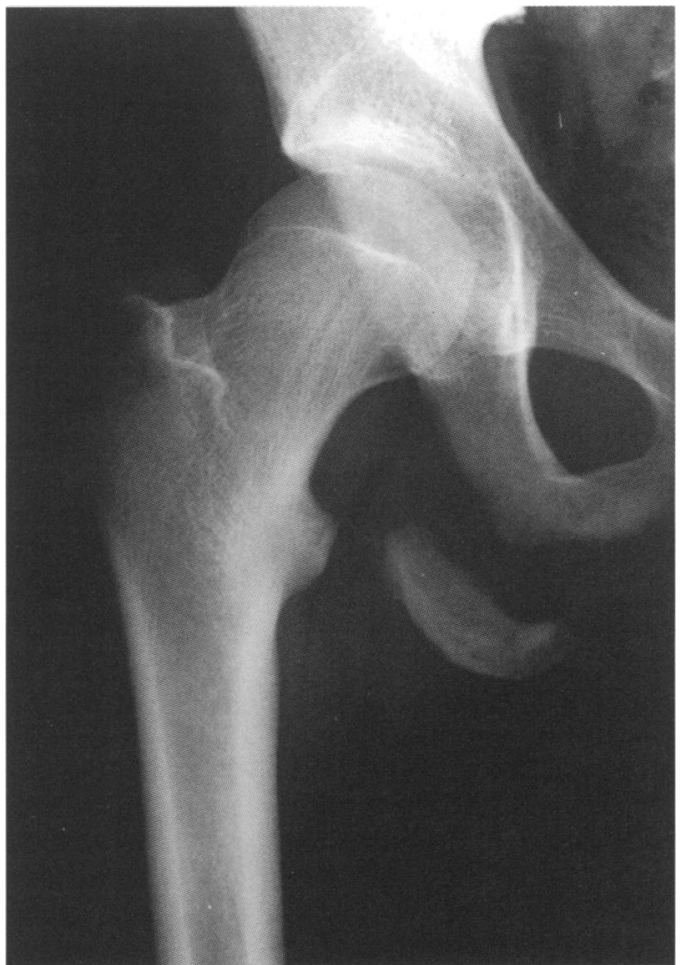

Figure 1 Avulsion of the right ischial apophysis.

avulsion is recommended if it is displaced more than $2 \mathrm{~cm}$. In such cases operative reduction and internal fixation will lead to fewer symptoms such as discomfort on sitting, subjective and objective muscle weakness, as well as a return to sporting ability. To aid early diagnosis, we advocate radiological investigation in those patients with suspected hamstring injuries with bony tenderness at the origin of the hamstrings or a palpable gap in this vicinity. If an avulsion of the ischial apophysis is found then orthopaedic referral should be made for possible operative fixation. stretching should not be advised for four weeks. Rehabilitation can begin at the time of diagnosis to maintain the general physical fitness of the athlete without stressing the injury. Secondly, surgical fixation of the
1 Kujala UM, Orava S. Ischial apophysis injuries in athletes. Sports Med 1993;16:290-4

2 Wotten JR, Cross MJ, Holt KW. Avulsion of the ischial apophysis. The case for open reduction and internal fixation. $\mathcal{F}$ Bone foint Surg Br 1990;72:625-7. 